\title{
Potential role for interferon- $\gamma$ release assays in tuberculosis screening in a remote Canadian community: a case series
}

\author{
Wilson Kwong MD MSc, Thomas Krahn, Ann Cleland, Janet Gordon, Wendy Wobeser MD MSc
}

\section{Abstract}

Background: Current Canadian guidelines suggest that neonatal Bacille Calmette-Guérin (BCG) vaccination does not result in false-positive tuberculosis (TB) skin tests, despite a growing body of evidence that interferon- $\gamma$ release assays may be a more specific alternative in identifying latent tuberculosis infections in vaccinated populations. We set out to evaluate the relationship between TB skin tests and interferon- $\gamma$ release assays in patients who previously received neonatal BCG vaccine.

Methods: All children with a positive skin test at age 14 years in a remote community north of Sioux Lookout, Ontario, were considered for interferon- $\gamma$ release assay testing.

Results: Of the 11 children who underwent routine screening at 14 years of age for latent TB infection, 7 had a positive TB skin test $(\geq 10 \mathrm{~mm}$ ). All 7 of these children had received the BCG vaccine as newborns and all had a negative TB skin test during their routine screening at 4 years of age. No potential exposure to active TB could be identified. Chest radiographs were normal, and none of the children had symptoms suggestive of active TB. The 7 children underwent interferon- $\gamma$ release assay testing using QuantiFERON Gold. All 7 tests were negative.

Interpretation: With the addition of interferon- $\gamma$ release assays to routine skin test screening, we provide evidence that neonatal BCG vaccination may contribute to a false-positive skin test in youth at 14 years of age. Consideration should be given to the possibility that neonatal BCG may contribute to false-positive TB skin tests.

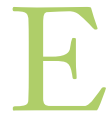
vidence that the Bacille Calmette-Guérin (BCG) vaccine can contribute to a false-positive tuberculosis (TB) skin tests has led to interferon- $\gamma$ release assays being a preferred option for identifying latent TB infection in vaccinated populations. ${ }^{1}$ Because of the complexity and cost of implementing interferon- $\gamma$ release assay testing, TB skin tests continue to be the predominant screening tool for latent TB infection in many Canadian jurisdictions. ${ }^{2,3}$

Although the BCG vaccine is not routinely used in most parts of North America, routine vaccination is still done in certain high-incidence communities. Specifically in Canada, infants from some First Nations and Inuit communities receive the BCG vaccine as newborns (within first $28 \mathrm{~d}$ after birth). Current recommendations from the Canadian Tuberculosis Standards (7th edition) state that the BCG vaccine, if given during infancy, should not be considered as a contributor to a false-positive TB skin test if the patient is older than 10 years of age. ${ }^{2}$ A growing body of evidence suggests that a proportion of positive skin test results among those who have received the vaccine may not be true-positives. ${ }^{4-8}$

False-positive TB skin tests could potentially contribute to unnecessary TB control activities and treatment for latent TB infection. We set out to examine the proportion of positive interferon- $\gamma$ release assays in a group of 14 year old children who did not have an identifiable TB risk factor.

\section{Methods}

\section{Setting}

A remote community north of Sioux Lookout, Ontario, was the site of our investigation.

\section{Study population}

Current policy supports BCG vaccine for newborns in this region, and children undergo routine TB skin testing for latent TB infection at 4 and 14 years of age. All children with

\section{Competing interests: None declared.}

This article has been peer reviewed.

Correspondence to: Wendy Wobeser, wendy.wobeser@queensu.ca CMAJ Open 2016. DOI:10.9778/cmajo.20160032 
a positive skin test at age 14 years in 1 community with no identified exposure were considered for interferon $-\gamma$ release assay testing. Interferon $-\gamma$ release assay testing was done within 6 months of the positive skin test result.

\section{Study design}

QuantiFERON Gold tubes were used and shipped to nurses in the community. Once the blood samples were collected, they were flown the same day to a hospital where they were incubated as per protocol, ${ }^{9}$ then shipped to Ottawa for further processing. All testing was completed between March and August 2014.

\section{Data sources}

Vaccination history, previous TB skin test results, active TB exposure and TB disease history were provided by the Sioux Lookout First Nations Health Authority. All data are maintained on site at the health centres of local communities under the guidance of the health authority. The maintenance of these records follows standard clinical practice and is supervised by the TB control program of the health authority. Consent for the TB skin test and interferon- $\gamma$ release assay was obtained from each child's guardian by a nurse in the community. This work was part of a program evaluation and was done by the Sioux Lookout First Nations Health Authority.

\section{Results}

Among the children with a positive skin test at age 14 years, 4 were excluded from participating in the study: 1 with prior BCG adenitis, 1 with a positive TB skin test at age 4 , 1 with a TB skin test wheal of $5 \mathrm{~mm}$, and 1 who was unavailable to participate. Seven children were eligible to participate in the study, all of whom had received the BCG vaccine as newborns and had a positive TB skin test at 14 years of age, with no identifiable risk factors for TB exposure. None of the 7 had positive test results with the QuantiFERON Gold assay $(0.00$ $\mathrm{IU} / \mathrm{mL}, 0.01 \mathrm{IU} / \mathrm{mL}, 0.00 \mathrm{IU} / \mathrm{mL}, 0.00 \mathrm{IU} / \mathrm{mL}, 0.00 \mathrm{IU} / \mathrm{mL}$, $0.03 \mathrm{IU} / \mathrm{mL}, 0.02 \mathrm{IU} / \mathrm{mL}$ ), and there were no indeterminate results. No samples were lost or ruined in transit. In addition, chest radiographs were all normal, and none of the children showed symptoms of active TB. No treatment for latent TB infection was initiated for these 7 children.

\section{Interpretation}

With the addition of interferon- $\gamma$ release assays to routine skin test screening, we provide evidence that neonatal BCG vaccination may contribute to a false-positive skin test in youth at 14 years of age. The growing body of evidence supports that a more targeted application of treatment of latent $\mathrm{TB}$ infection can be accomplished in response to adding interferon- $\gamma$ release assays to the screening protocol. ${ }^{1,4-8}$

The findings of this study are in agreement with other studies that have anchored interferon $-\gamma$ release assays as a more specific test than the skin test for people who have received the BCG vaccine. The work of Katsenos and col- leagues suggested that BCG vaccination after infancy contributed substantively to a false-positive skin test. ${ }^{5}$ Although evidence supports the idea that induration size is predictive of concordance with interferon $-\gamma$ release assays, there remain a number of skin tests even at larger size that may we be falsepositive results. ${ }^{4,6}$ Although these studies all involved adults, Jacobs and colleagues performed a similar analysis among First Nation children in Alberta, and once again documented false-positive skin test results with previous BCG vaccination. ${ }^{7}$

Ensuring that samples were incubated in the appropriate setting and for the appropriate duration was logistically challenging in this small community. Careful organization of collection of samples and alignment with availability of the relatively limited shipping capabilities is necessary. A multidisciplinary approach involving numerous jurisdictions was required to coordinate interferon $-\gamma$ release assay testing in our investigation. Most recently, Alvarez and colleagues conducted interferon $-\gamma$ release assay testing in Iqaluit, Nunavut, and showed that such testing was feasible for 256 people. ${ }^{8}$ Similar to previous studies, a high degree of discordance between skin test and interferon- $\gamma$ release assay results was noted in people who had previously received the BCG vaccine. Outside of Canada, Soborg and colleagues also presented data suggesting the potential for false-positive skin test results when the interferon- $\gamma$ release assay is not used in the Inuit population. ${ }^{10}$

\section{Limitations}

It should be noted that although the small community in question had a 10-year average incidence rate of smear positive TB of 13.4 per $100000,{ }^{11}$ our efforts to uncover any sick contacts (including active TB contacts) among the children who underwent testing all proved to be negative. It appears unlikely that recent contact with an active TB patient would have influenced the current study results. However, the possibility of nontuberculous mycobacteria causing a positive skin test result cannot be ruled out with the current study's data. On the contrary, recent studies have documented some of the limitations of the interferon- $\gamma$ release assay. ${ }^{12}$ As with the TB skin test, the sensitivity of the interferon- $\gamma$ release assay in immunocompromised patients has been questioned given that this population is most susceptible to latent TB infection. ${ }^{13}$ In addition, the interferon $\gamma$ release assay has been shown to be less accurate in younger children. ${ }^{14}$ Lastly, as mentioned in this current study, the costs and logistics of implementing interferon $\gamma$ release assay testing need to be considered when recommending its use in smaller communities.

\section{Conclusion}

There is a need for considering the role of interferon- $\gamma$ release assay testing in adolescents with positive TB skin test results who have received the BCG vaccine as newborns. Implementing such practices into First Nation communities must take into account the unique and remote conditions inherent to these populations. The costs and logistics of implementing interferon $-\gamma$ release assay testing need to be considered when recommending its use in smaller communities. 


\section{References}

1. Pai M, Riley LW, Colford JM Jr. Interferon-gamma assays in the immunodiagnosis of tuberculosis: a systematic review. Lancet Infect Dis 2004:4:761-76.

2. Canadian tuberculosis standards 7th edition. Ottawa: Public Health Agency of Canada; Lung Association; Thoracic Society; 2014. Available: www.respiratoryguidelines. ca/sites/all/files/Canadian_TB_Standards_7th_Edition_ENG.pdf (accessed 2014 Dec. 15).

3. Updated guidelines for using interferon gamma release assays to detect mycobacterium tuberculosis infection - United States. MMWR 2010;59:1-25. Available: www.cdc.gov/mmwr/preview/mmwrhtml/rr5905a1.htm (accessed 2014 Dec. 15).

4. Tissot F, Zanetti G, Francioli P, et al. Influence of bacille Calmette-Guérin vaccination on size of tuberculin skin test reaction: To what size? Clin Infect Dis 2005;40:211-7.

5. Katsenos S, Nikolopoulou M, Konstantinidis AK, et al. Interferon-gamma release assay clarifies the effect of bacille Calmette-Guérin vaccination in Greek army recruits. Int 7 Tuberc Lung Dis 2010;14:545-50.

6. Mahan CS, Johnson DF, Curley C, et al. Concordance of a positive tuberculin skin test and an interferon gamma release assay in bacille Calmette-Guérin vaccinated persons. Int 7 Tuberc Lung Dis 2011;15:174-8, i.

7. Jacobs S, Warman A, Richardson R, et al. The tuberculin skin test is unreliable in school children BCG-vaccinated in infancy and at low risk of tuberculosis infection. Pediatr Infect Dis 7 2011;30:754-8.

8. Alvarez GG,Van Dyk DD, Davies N, et al. The feasibility of the interferon gamma release assay and predictors of discordance with the tuberculin skin test for the diagnosis of latent tuberculosis infection in a remote aboriginal community. PLoS One 2014;9:e111986.

9. QuantiFERON-TB Gold (QFT) ELISA package insert. Victoria (AU): Qiagen; 2013. Available: www.quantiferon.com/irm/content/PI/QFT/2PK/UK.pdf (accessed 2014 Dec. 15).

10. Soborg B, Koch A, Thomsen VØ, et al. Ongoing tuberculosis transmission to children in Greenland. Eur Respir 7 2010;36:878-84.

11. Evaluation of BCG vaccine in Sioux Lookout zone: a joint statement from the BCG Immunization Advisory Committee. Sioux Lookout (ON): BCG Immunization Advisory Committee; 2013.
12. Tebruegge M, Ritz N, Curtis N, et al. Diagnostic tests for childhood tuberculosis: past imperfect, present tense and future perfect? Pediatr Infect Dis 7 2015;34:1014-9.

13. Haustein T, Ridout DA, Hartley JC, et al. The likelihood of an indeterminate tes result from a whole-blood interferon-gamma release assay for the diagnosis of Mycobacterium tuberculosis infection in children correlates with age and immune status. Pediatr Infect Dis 7 2009;28:669-73.

14. Tebruegge M, de Graaf H, Sukhtankar P , et al. Extremes of age are associated with indeterminate QuantiFERON-TB gold assay results. 7 Clin Microbiol 2014;52:2694-7.

Affiliations: Department of Medicine (Kwong), University of Toronto, Toronto, Ont.; Department of Medicine (Krahn, Wobeser), Queen's University, Kingston, Ont.; Sioux Lookout First Nations Health Authority (Cleland, Gordon), Sioux Lookout, Ont.

Contributors: Wilson Kwong was involved in study design, data collection, data analysis and writing. Thomas Krahn was involved in data analysis and writing. Ann Cleland was involved in data collection, data analysis and writing. Janet Gordon was involved in data analysis and writing. Wendy Wobeser was involved in study design, data collection, data analysis and writing. All of the authors approved the final version to be published and agreed to acts as guarantors of the work.

Acknowledgements: The authors would like to acknowledge the Sioux Lookout First Nations Health Authority for their support in implementing this study.

Supplemental information: For reviewer comments and the original submission of this manuscript, please see www.cmajopen.ca/content/4/3/ E535/suppl/DC1 